\title{
DA ALERGIA À ALTERIDADE A READMISSÃO DO OUTRO: A PRESENÇA DE EMMANUEL LÉVINAS NA PROPOSTA ÉTICA DE ZYGMUNT BAUMAN
}

\author{
Milena de Lima Barbosa ${ }^{1}$ \\ Rafael Bianchi Silva ${ }^{2}$
}

\begin{abstract}
Resumo:
Nas discussões sobre a constituição da subjetividade, o debate sobre o papel do Outro é algo relativamente recente. O objetivo do artigo é discutir esse processo a partir da alteridade e a construção de uma ética para a contemporaneidade tendo por base o debate realizado pelo sociólogo Zygmunt Bauman em especial, quanto ao diálogo realizado com o pensamento de Emmanuel Lévinas e sua ética radical. Após uma breve contextualização do pensamento moderno na qual temos, para Lévinas, uma "alergia a alteridade" é apresentado o conceito de Rosto como expressão da alteridade, numa perspectiva na qual o Outro não é reduzido ao mesmo, não sendo identidade nem limite do eu. Da alteridade dá-se a produção de um sujeito ético, em Lévinas, entendido como responsável pelo Outro. Esse é um dos fundamentos para a proposição ética de Zygmunt Bauman que parte da crítica a universalização de normativas de conduta e a dificuldade de relacionamento na sociedade contemporânea. Desse modo, a contemporaneidade nos exige uma nova forma de tratar as questões vinculares, abrindo possibilidades de, através das emoções e afetos, resgatar a alteridade dos relacionamentos.
\end{abstract}

Palavras-chaves: Zygmunt Bauman. Emmanuel Levinas. Contemporaneidade. Ética

\section{FROM ALLERGY TO ALTERITY THE READMISSION OF THE OTHER: THE PRESENCE OF EMMANUEL LÉVINAS IN ZYGMUNT BAUMAN'S ETHICAL PROPOSAL}

\begin{abstract}
:
In discussions on the constitution of subjectivity, the debate on the role of the Other is something relatively recent. The purpose of this article is to discuss this process from the alterity and the construction of an ethics for contemporaneity based on the debate conducted by sociologist Zygmunt Bauman in particular, regarding the dialogue performed with the thought of Emmanuel Lévinas and his radical ethics. After a brief contextualization of modern thought in which we have, for Lévinas, an "allergy to alterity" is presented the concept of Face as an expression of alterity, in a perspective in which the Other is not reduced to the same, not being identity or limit of the self. The production of the ethical subject takes place from the alterity, in Lévinas, understood as responsible for the Other. This is one of the fundaments for Zygmunt Bauman's ethical proposition, that criticizes the universalization of conduct norms and the relationship difficulties in contemporary society. Thus, contemporaneity requires a new way of dealing with the bond issues, opening possibilities to, through emotions and affections, rescue the alterity of relationships.
\end{abstract}

Keywords: Zygmunt Bauman. Emmanuel Levinas. Contemporaneity. Ethics

\footnotetext{
${ }^{1}$ Mestre em Psicologia pela Universidade Estadual de Londrina (Londrina, 2019-2021). Psicóloga da Universidade Tecnológica Federal do Paraná, campus Cornélio Procópio. Contato: milenabarbosa@utfpr.edu.br

${ }^{2}$ Pos-Doutor em Psicologia pela Universidade Estadual de Maringá (UEM). Doutor em Educação pela Unesp/Marília. Docente do Programa de Pós-Graduação em Psicologia da Universidade Estadual de Londrina (UEL). Membro do GP Filosofia, educação e condição humana da Universidade Estadual de Londrina. E-mail: rafael.bianchi@uel.br
} 


\section{Introdução}

A construção da subjetividade no contexto contemporâneo tem como um de seus principais operadores a questão do outro atravessado pelos conceitos de alteridade e diferença. Embora o Outro seja uma aquisição recente nas discussões sobre a constituição da subjetividade, pensar a alteridade como constitutiva desta é cada vez mais uma exigência ética nos dias atuais em diferentes campos do conhecimento (FIGUEIREDO ET AL, 2004)

O objetivo desse artigo é analisar a correlação desses elementos a partir do debate realizado pelo sociólogo polonês Zigmunt Bauman na problematização em torno do tema da ética de modo a investigar, em especial, o diálogo realizado pelo autor com o pensamento de filósofo Emmanuel Lévinas e sua ética radical para pensarmos os efeitos para os processos formativos no contexto contemporâneo.

Inicialmente, é importante realizar uma breve retomada para que seja possível mapear as questões debatidas pelos autores. De modo geral, ainda que partindo de pontos diferentes, ambos colocam suas atenções para a forma com que a filosofia moderna tratou a questão ética, o que implica em um debate sobre o lugar do outro no que tange a produção de si.

Segundo Junior (2010), a partir da primeira metade do século XIX, a noção de modernidade passa a ser usado no sentido de tempo presente transitório, que está destinado a ser superado por um futuro. Comparada ao período clássico dominado pelo pensamento religioso, realiza uma avaliação crítica deste enquanto organizador da vida societária. Em contraposição, propõe a valorização da racionalidade humana na condução dos problemas da vida comum, o que envolve um entendimento das questões que englobam a vida societária (CANDIOTTO, 2010).

Descartes através do aforisma "Penso, logo existo", demarca um lugar para um eu que ultrapassa a dimensão sensível, o cogito cartesiano. Sintetiza, assim, ideias chaves da modernidade: do ser singular que tem a experiência mediada pela razão e, a partir dela, do mundo como experiência interna do indivíduo (BOCK ET AL., 2008).

O pensamento moderno tem assim como a formulação de uma oposição sujeitoobjeto cartesiano e a ascensão da primazia da razão (FIGUEIREDO ET AL., 2004). Ambos se tornam base para a centralização do sujeito que possui independência em relação a experiência relativa ao campo vivido exterior e, consequentemente, aos outros sujeitos que fazem parte desse mesmo mundo.

\begin{tabular}{|l|l|l|l|l|}
\hline Q & Anista \\
\hline
\end{tabular}


A modernidade apoia-se no conceito de um eu singular e de uma identidade privada que refletem numa visão também singular do mundo forjada no individualismo (JAMENSON, 1985). No pensamento filosófico moderno, a subjetividade é concebida com base neste ideal de sujeito livre e soberano. O Eu é a unidade integradora que ergue sua subjetividade sobre as bases de uma vontade racional (MIRANDA, 2014). Desse modo, a constituição de uma dimensão subjetiva está intimamente vinculada com a existência de um Eu que independe da existência do Outro, sendo assim, auto constituído e autocentrado. (FIGUEIREDO ET AL., 2004).

Considerando a presença de outros seres presentes no campo relacional, a problematização do papel do outro na produção da subjetividade, torna-se um tema recorrente de preocupação para os pensadores modernos. No diagnóstico realizado por Hermann (2011) acerca dos lugares do outro na modernidade, este é visto inicialmente, como problema, associado a presença de um estranho. Enquanto seu contrário, ou seja, distinto do eu, a presença da alteridade, considerada como limite do Eu, demarca lugares e posicionamentos que precisam ser tomados em relação ao Outro.

Será a partir dessa necessidade de responder a presença de um ser diferente de si mesmo que percorreremos o modo como Bauman desenvolve suas análises em torno da questão ética tendo em Lévinas seu principal interlocutor:

[...] De facto, se a ética moderna se constituiu e se desenvolveu à volta do 'EU' e da sua consciência, a ética de Bauman e Levinas se constrói à volta da perspectiva do 'outro' e da relação de alteridade. Por isso, esta ética pode designar-se pós-moderna, quando o 'outro' e a relação de alteridade aparecem na entranha constitutiva do 'EU' subjectivo e individual, em que a sua autonomia individual fica substituída pela proximidade do 'outro'. É o 'outro' que se interpõe no processo de construção da identidade individual, ficando diferida essa identidade ou substituída por responsabilidade (MARTINS, 2007, p.35).

Para realizar o aprofundamento dessa discussão, o trabalho foi realizado em duas momentos. Na primeira, será apresentado a proposta de Emmanuel Lévinas de pensar a subjetividade a partir da alteridade e como ocorre a construção ética em seu pensamento. $\mathrm{Na}$ segunda parte é apresentado, a partir do pensamento de Zygmunt Bauman e sua proposta de ética para o mundo contemporâneo considerando as contribuições de Lévinas.

Antes disso, porém, faremos uma breve introdução de como a questão ética é problematizada por Bauman de modo a compreender sua aproximação com as ideias do filósofo lituano.

Da ética à moralidade: introduzindo a questão

\begin{tabular}{|c|c|c|c|c|}
\hline Qevista Dialectus & Ano 10 & n. 22 & Edição Especial, junho 2021 & p. 84- 97 \\
\hline
\end{tabular}


Na obra de Bauman, o debate em torno da questão ética, passa necessariamente pela crítica do modo como o pensamento moderno operou a questão. A partir da visão do autor, a realidade humana é cheia de ambiguidades. A expansão da racionalidade no contexto da primeira modernidade (utilizando o termo utilizado por BECK, 2010) é uma tentativa de dar sentido ao mar de indeterminações ao qual todos estou submetidos. Esse processo será realizo através de diferentes instituições sociais que possuem a função de "fábricas de ordem" que tornam as situações virtualmente possíveis em algo previsíveis e, portanto, passíveis de intervenção (BAUMAN, 1998).

Bauman (2003) pontua que o uso da razão, em sua sede de ordenação e controle da vida, realizou no campo da ética a planificação da existência em torno da obediência a códigos de conduta empregados enquanto normativas. Desse modo, ao invés de uma relação efetiva com o outro, passamos a ter uma relação primeira com as leis que governam a conduta o que confere a própria relação um estatuto secundário.

Diferentemente de propor a reformulação dos códigos éticos, o autor reposiciona a questão da moralidade como centro para o enfrentamento da mecanização da vida realizada através do projeto de universalização ética. Para tanto, rompe com a premissa moderna de dicotomização entre a ordem - caracterizada como produto da razão - e o caos - efeito da dimensão emocional.

Essa mudança de perspectiva é uma das marcas do pensamento contemporâneo, responsável, através do questionamento de suas premissas, produzir uma modernidade sem a ilusão de que o domínio ordenado e sistemático da razão irá pôr fim a confusão ambígua da realidade. Por essa razão, para Bauman (2003) é necessário repersonalizar a moral aprendendo a respeitar as ambiguidades e considerar as emoções humanas. Não se trata, porém, de um processo simples, mas sim, um exercício a ser realizado nas relações estabelecidas ao longo da vida.

Os filósofos da ética moderna tentaram demonstrar que atender aos mandamentos morais é do próprio interesse de quem o faz, estabelecendo assim uma relação de auto interesse e preocupação com os outros baseados em argumentos que se fortalecem em pressupostos da assertiva de que "se você for bom com os outros, os outros serão bons para você".

Porém, na prática, esta lógica de custo-benefício não conseguiu sustentar seus argumentos. Deste modo, não existe um deve na moral: "Paradoxalmente (ou nem tanto) seguir as demandas éticas significa esquecer seu poder coercitivo. Seguir as demandas éticas significa ser guiado unicamente, pelo bem do Outro" (BAUMAN, 2003, p.177)

\begin{tabular}{|c|c|c|c|c|}
\hline QRovista Dialactus & Ano 10 & n. 22 & Edição Especial, junho 2021 & p. 84- 97 \\
\hline
\end{tabular}


Desse modo, é possível indicar que, se a ética está no plano das regulamentações/normas, a dimensão moral encontra-se no plano das individualidades, o que engloba as vivências subjetivas. Em uma relação governada por regras os atores não se confrontam com outras pessoas e a verdadeira relação é entre o ator e as regras. A outra pessoa torna-se apenas um peão no tabuleiro de direitos e deveres. Assim temos um existir com se esgota em cumprir regras (BAUMAN, 2011)

A análise dos fundamentos da conduta sai da esfera da razão e do projeto de configurar-se enquanto princípio universal. Diferentemente disso, Bauman (2009) considera que a moralidade é campo anterior ao eu pensante e, por isso, os princípios norteadores da conduta encontram-se articulados com a dimensão do impulso moral.

Nesse ponto, é possível estabelecer um comparativo crítico entre sua posição e a anterior. Afirma que "[...] quando conceitos, padrões e regras entram no palco, o impulso moral faz sua saída, o raciocínio ético toma seu lugar, mas a ética é feita a semelhança da Lei, não do impulso moral (BAUMAN, 2003, p.73).

Se a modernidade atual (caracterizada pela condição de liquidez) é marcada pela queda - ainda que se encontrem presentes e influentes - de instituições historicamente sólidas (como o Estado, a Religião e a família) no que tange a determinação de regimes de conduta considerados como válidos pelo tecido social, quais serão os caminhos possíveis aos sujeitos para modular sua conduta?

Para responder essa questão, de modo a escapar da racionalidade abstrata, considerada pelo autor como uma das marcas da modernidade, será tomado um caminho no qual o eu ético poderá dar atenção ao 'outro/a' e de estabelecer uma relação com ele (MARTINS, 2007).

\section{Lévinas e a ética radical}

A operação realiza por Bauman se encontra alinhada e fundamentada no diálogo realizado pelo autor com as preocupações indicadas por Emanuel Lévinas. O modo de pensar a subjetividade, no pensamento moderno, centrado no Eu soberano, criou como diz Lévinas uma "alergia a alteridade". Desta maneira, foi criada uma espécie de filosofia do mesmo: de eu voltado a si, constituído pela assimilação do Outro, que por sua vez é pensado a partir da identidade do Mesmo (MIRANDA, 2008).

Nesta perspectiva, a alteridade é somente um meio do sujeito reconhecer-se como consciência de si. O diferente é um espelho que reflete o eu em ação fundamental para a

\begin{tabular}{|c|c|c|c|c|}
\hline Qevista Dialectus & Ano 10 & n. 22 & Edição Especial, junho 2021 & p. 84- 97 \\
\hline
\end{tabular}


formação de uma imagem subjetiva de si. Hermann (2011, p.120) sintetiza essa posição ao afirmar que "O Outro existe para que o próprio sujeito possa reconhecer-se".

Diferentemente disso, a alteridade em Lévinas se mostra como uma irrupção e ocorre como um evento modificador para o vivente. Por essa razão, o sujeito reconhece a alteridade enquanto experiência de subjetivação, não sendo, portanto, simplesmente uma assimilação do outro, mas ao contrário, uma impossibilidade de identidade e adaptação a este que difere.

Deste modo, o Outro é sempre vivenciado como exceção (o que difere a regra) e transposição de algo sobre si. Conforma explicam Figueiredo et al. (2004, p.21), "a alteridade, nessa dimensão, é traumática porque produz fraturas e exige trabalho em processos permanentes de inadaptação entre Eu e o Outro".

Lévinas realiza uma crítica ao pensamento filosófico baseado na autonomia e independência do ser que acaba por submeter o Outro ao Mesmo. O Eu e o Outro não formam uma totalidade assim como o Eu não é oposto do Outro. Percebe-se uma crítica que tensiona o discurso fundado no ser enquanto fundamento da realidade, o que para ele suplanta a alteridade. (Freire, 2009). Segundo Lévinas (1980, p.31) “conhecer ontologicamente equivale a captar o ser a partir de nada ou reduzi-lo a nada, arrebatar-lhe a sua alteridade".

O acesso a alteridade do Outro não é uma percepção do Eu. Sendo assim, o Outro não é conceituado a partir do Eu. Para Levinas (2014, p.8-9), quando tematizamos o Outro estamos o expropriando de sua alteridade, de forma que temos que falar ao Outro antes mesmo de falar dele: "se dele falar, já é dilacerar a relação, falar a ele significa fazer com que sua alteridade se realize".

Isso faz com que seja necessário abrir mão do esforço de buscar descrever a relação com a outra pessoa através da sua redução à compreensão. Por isso, o problema das relações implica em experienciar a relação face-a-face. Caso esse processo fracasse, somos impossibilitados do reconhecimento da humanidade do outro, o que é campo fértil para diferentes tipos de atentados a vida como observado nos genocídios (caso do Holocausto), por exemplo.

Até o momento, temos um cenário no qual, há a impossibilidade de conhecer o Outro em sua totalidade ao mesmo tempo em que se vê a necessidade de ver nele sinal de humanidade, o que é base para o exercício de cuidado. O desdobramento desse diagnóstico é explicado por Critchley $(2008$, p.18) ao afirmar que “[...] em nossas relações com as outras pessoas, temos que aprender a reconhecer o que não podemos conhecer [...]. O fim da certeza

\begin{tabular}{|c|c|c|c|c|}
\hline Qevista Dialectus & Ano 10 & n. 22 & Edição Especial, junho 2021 & p. 84- 97 \\
\hline
\end{tabular}


pode ser o início da confiança". Assim, a possibilidade de ser para o outro configura-se como um acontecimento ético (FREIRE, 2009), responsabilidade pessoal e intrasferível em relação ao Outro.

Esse processo acontece pela presentificação pelo Outro como Rosto, abertura da sua humanidade. O Rosto é expressão da alteridade, modo de fazer referência ao Outro como potência expressiva (NAVARRO, 2007). Sendo negação a se circunscrever enquanto conteúdo, é nele que se exibe toda a desmesura da alteridade, marcado pela fragilidade e potência que o diferente mostra na relação face-a-face. A incapacidade de descrever de modo objetivo o Outro em relação ao Mesmo é o elemento principal que o Rosto nos traz aplicando a ideia de infinito a alteridade.

O infinito é uma noção cujo conteúdo é totalmente filosófico. Trata-se da exteriorização do pensamento, pensar mais do que pode ser pensado. A ideia do infinito, portanto, não se deixa representar. O infinito é o radicalmente, absolutamente Outro e é exatamente esse traço que é caracterizado e reconhecido do Rosto.

Por essa razão, conforme Zanon (2020), a experiência da alteridade tem íntima conexão com o modo como a ideia do infinito assola a mesma interioridade causa efeito na produção do que chamamos de consciência. Assim, “[...] a relação de alteridade parte da capacidade do 'rosto', de uma mera presença do outro, de questionar os poderes e a autoridade da consciência do eu" (NAVARRO, 2007, p.183).

O Outro, que nos apresenta como Rosto, impele a tomada de posição que, em suma, efetiva-se, enquanto responsabilidade. Como bem nos relembra Derrida (2008), ao ser interpelado pelo apelo e nudez do Rosto, coloca-se, sobre cada um, a responsabilidade de responder por ele. Esta responsabilidade que o rosto impõe ao eu, segundo Lévinas (2014, p.28), "uma responsabilidade gratuita - e inalienável, como se o eu fosse escolhido e único [...]" desdobra-se na experiência do Outro enquanto infinito, radicalidade.

Nela, o Rosto impõe uma resposta do eu, sendo que a resposta esperada é a reciprocidade da presença do eu em sua condição de responsável pelo cuidado do Outro. Para Lévinas (2004), além desta responsabilidade não poder ser transferida, também não se exige obrigatoriamente reciprocidade. Por essa razão, a relação do Rosto é assimétrica. Nas palavras de Haddock-Lobo (2006, p.139), a ética trata:

[...] da experiência da assimetria significada na epifania da face do outro, ou, mais propriamente, na linguagem. Mais do que uma relação, a experiência mesma é a relação que se estabelece no infinito espaço assimétrico entre eu e outro, e é estampada

\begin{tabular}{|c|c|c|c|c|}
\hline Qevista Dialectus & Ano 10 & n. 22 & Edição Especial, junho 2021 & p. 84- 97 \\
\hline
\end{tabular}


na nudez do rosto deste que me convoca à palavra, que me invade violentamente com a demanda ética e que, por isso, me institui como eu.

A responsabilidade não é resultado, portanto, de uma tomada de decisão de uma vontade livre individual, mas sim, constitui o fundamento da própria subjetividade. A subjetividade enquanto responsabilidade para com o Outro, estabelecendo assim, uma identidade da subjetividade com a responsabilidade. Isso é expresso na afirmação do autor afirma ao dizer que: "No começo pouco me importa o que o Outro é em relação a mim, isto é problema dele, para mim ele é antes de tudo aquele por quem eu sou responsável" (LÉVINAS, 2004, p.145)

Vemos, portanto, que o princípio da relação ética em Lévinas está presente no vínculo com o Outro - marcado pela face-a-face e horror proporcionado pelo Rosto - e não pela autonomia do eu soberano que legisla sobre a existência e os modos de ser do diferente. Segundo o autor (2004, p.177), "na deposição pelo eu de sua soberania de eu, na sua modalidade de eu detestável, significa a ética”.

Como apresentado o modelo de subjetividade baseado no discurso da ontologia presente e disseminado na modernidade pressupõe a compreensão do ser a partir da identidade e para a totalidade. Por sua vez, a subjetividade em Lévinas se dá para o Outro e a partir daí que podemos falar de propriamente de efetiva relação pelas vias da alteridade. Isso é expresso na síntese realizada por Carrara (2012, p.36) ao afirmar, nessa perspectiva, “[...] é a ética esta possibilidade de impugnar minha espontaneidade pela presença de Outrem. A ética é a possibilidade de abordar a estranheza de Outrem, sua impossibilidade de ser reduzido ao Mesmo, ao pensamento e às posses do Mesmo".

\section{A admissão do Outro}

Como vimos na seção anterior, para Lévinas a responsabilidade pelo Outro é estruturante para subjetividade, sendo esta constituída a partir e para o Outro. Nesse sentido, como bem nos lembra Haddock-Lobo (2006), a proposição ética problematizada pelo autor reitera "[...] a devoção que o Mesmo deve apresentar diante do outro, anterior à sua formação mesma como sujeito [...] ". Será esse o espaço propício para os elementos que Bauman trará na discussão a respeito da ética.

Silva (2018, p.121) afirma que, para Bauman, “[...] a face do outro mostra a fragilidade de ambos os envolvidos na relação, o que justifica o necessário compromisso moral que tem no amor sua maior expressão [...]". Esta responsabilidade que se reflete no cuidado e

\begin{tabular}{|c|c|c|c|c|}
\hline Q Rovista Dialeatus & Ano 10 & n. 22 & Edição Especial, junho 2021 & p. 84- 97 \\
\hline
\end{tabular}


na preocupação com o outro é materializada no que o autor chama de "ser-para", sendo que a moral está identificada com essa posição (BAUMAN, 2009).

Diferente de estar próximo ao outro ou mesmo de estar com o outro, na posição de ser-para encontramos a vontade de servir, fazer bem, de expressar amor ao diferente. Bauman (2011, p.87) afirma que se trata do domínio da simpatia, ou seja, capacidade de colocar-se no lugar do sofrimento do outro, o que implica em ter uma "[...] disposição para servir, para fazer o bem, para o autossacrifício pelo outro".

Desta maneira, ser-para está relacionado com assumir a reponsabilidade pelos Outros, entendendo-a como única e somente minha (BAUMAN, 2011). Esse processo ainda que possa ser visto como de grande peso para o vivente, ele é de extrema importante para a constituição de si visto que há ser e ser para os outros, para o autor, são sinônimos: é a série de responsabilidades assumidas ao longo da vida em relação ao outro que produz o tecido que dá contornos ao eu (BAUMAN, 2009). Por essa razão, neste modo de relação, não se exige reciprocidade e é nisto que reside o centro da responsabilidade moral (em suma, assimétrica). De acordo com o autor, "é essa unicidade (não generalizabilidade) e essa não reversibilidade da minha responsabilidade, que me coloca no relacionamento moral" (2003, p.63).

Mas como ocorre a passagem de estar com o outro para o ser-para? Neste último, Bauman (2011) indica a necessidade de um empenho emocional ao Outro, o que aponta para uma abertura a formas específicas de sentir e isso estaria vinculado a noção de proximidade. $\mathrm{O}$ autor (1998) aponta que há uma relação diretamente proporcional entre a presença e a possibilidade de cuidado com o Outro, visto que sua existência se articula com sua proximidade. Por isso afirma que:

\begin{abstract}
A responsabilidade, esse tijolo constitutivo de todo comportamento moral, surge da proximidade do outro. Proximidade significa responsabilidade e responsabilidade é proximidade. A discussão da prioridade relativa de uma ou de outra é reconhecidamente gratuita, pois nenhuma é concebível sozinha [...] A responsabilidade é silenciada uma vez desgastada a proximidade; pode eventualmente ser substituída pelo ressentimento, uma vez o co-sujeito humano seja transformado num Outro. $O$ processo de transformação é de separação social. Foi tal separação que tornou possivel que milhares matassem e milhões assistissem o assassinato sem protestar (p.212-213, grifo do autor).
\end{abstract}

A proximidade está intimamente relacionada com a possibilidade do Rosto e, como desdobramento, ser afetado pela sua existência. Enquanto conceito,

$\mathrm{O}$ afeto tem o poder de determinar o jeito da pessoa, a forma de se posicionar, de colocar em prática suas ações, condutas e pensamentos, à maneira como criam os laços de afetividades [...] corresponde a uma gama de sentimentos associados à história de vida de uma pessoa, sendo responsável em estruturar os laços de

\begin{tabular}{|l|l|l|l|l|}
\hline Govista Dialectus & Ano 10 & n. 22 & Edição Especial, junho 2021 & p. 84- 97 \\
\hline
\end{tabular}


subjetividade pessoais, como lealdade, empatia, enfrentamentos, respeito (BITTENCOURT, 2019, p.165).

Assim, é esse processo que permite sair do estado de indiferença e impele o Outro para fora do mundo da certeza e lança ao munda da abertura. Além disso, é através dela que se consegue tirar o Outro do mundo das normas e regras universais. Como bem afirma Bauman (2010, p.66), “[...] a outredade do outro é equivalente a sua unicidade; cada rosto é único e exclusivo, e sua unicidade desafia a impessoalidade endêmica da norma".

É através do exercício do empenhamento emocional que o Outro se transforma numa tarefa própria do e para o sujeito. Bauman (2011, p.92) afirma que há uma especificidade no processo de responsabilização pelo diferente que ultrapassa a dimensão da norma:

\footnotetext{
Mas estar ligado ao outro pela emoção significa, por outro lado, que sou responsável por ele/ela, e sobretudo pelo que minha ação ou inação possa lhe fazer. Não sou não mais uma cifra, um item intercambiável de um conjunto, uma fresta corrigível na rede de relações. O que faço faz diferença - e fará igualmente diferença se eu desistir de fazê-lo. Agora o outro se torna meu refém; e eu, por minha vez, torno-me refém de minha responsabilidade.
}

Esse jogo dual no que diz respeito à alteridade é problematizado por Bauman de diferentes formas ao longo de sua obra. Um desses modelo é descrito pelo autor ao discorrer sobre as escolhas realizadas na vida. O autor pontua (2009) que, quanto ao diferente, podemos tomar uma atitude centrípeta ou centrifuga. Estar no polo centrifugo (no qual Lévinas é portavoz), implica dirigir-se do centro em direção às extremidades - para fora - o que indica uma descentralização do eu. Em contrapartida, a direção centrípeta aponta para o afastamento da dispersão, voltando-se ao centro - ao eu - levando ao afastamento do outro.

O mesmo processo é descrito por Bauman na diferenciação entre duas posições chamadas de mixofobia e mixofilia. A primeira indica o medo em relação ao diferente. Bauman (2003) explica que a ansiedade nasce da dissolução da face do Outro nos "Muitos". Visto que usamos máscaras cotidianamente, elas se tornam uma espécie de proteção às faces e o que elas revelam. Assim, “[...] deve-se confiar (até certo ponto) nas máscaras, goste ou não e deve-se viver com essa ansiedade [...]" (SILVA, 2012, p.101).

Em contrapartida, a posição mixofílica indica a potência para aproximação à diferença. Observa-se aqui que ao apontar para a proximidade, retoma-se um balizamento ético já indicado anteriormente pelo autor e com ele, um tipo de relação de frente ao estranhamento e aos desafios que a impossibilidade de categorização do Rosto impõe. Nesse sentido, é um ato 
de coragem pois implica a cada um adentro do infinito de possibilidades expressas na relação com o diferente.

A partir dos elementos aqui levantados podemos dizer que, para Bauman (2003), a produção de uma ética no contemporâneo não significa abandonar os conceitos morais, mas sim rejeitar a maneira moderna de tratar os problemas morais, através de regulamentações, normativas e pela busca filosófica de absolutos universais. Para tanto, "o outro, como uma arte inquieta e imprevisível, como o próprio futuro, é um mistério. E ser-para-o-outro, ir ao encontro do outro pelo tortuoso e rochoso desfiladeiro da afeição, lança luz sobre esse mistério transforma-o num desafio [...]" (BAUMAN, 2011, p.98).

Ao afastar-se de normativas que fazem a mediação da relação com o outro (inclusive pelo enfraquecimento institucional atual), retoma-se uma espécie de solidão existencial nas microrrelações face-a-face (SILVA, 2013). Esse ponto sustenta o entendimento do autor de que a relação com o outro se trata de uma decisão - uma escolha que independe necessariamente das condições e influência do meio social - a ser enfrentada, o que confere sentido a dimensão da condição de ambivalência moral experienciada por cada ser humano:

\begin{abstract}
A obediência à demanda ética na linha de seguir uma ordem pelo medo de sanções punitivas que recairiam sobre o desobediente não seria a ação moral pretendida pela demanda ética. Conformidade não é moralidade, mesmo que em resposta a uma ordem de fazer determinado bem. Não existe um "deve" na moral - nada de ordens nem coerção; as ações morais são intrinsecamente escolhas livres, expressões da liberdade de ação do eu (seres humanos não-livres - se essa contradição em termos fosse plausível - não seriam "seres morais"). Paradoxalmente (ou nem tanto), seguir as demandas éticas significa esquecer seu poder coercitivo. Seguir as demandas éticas significa ser guiado unicamente pelo bem do Outro (BAUMAN, 2009, p.138, grifo do autor).
\end{abstract}

\title{
Reflexões Finais
}

E qual o impacto para formação humana na contemporaneidade? Se vivemos em um contexto pautado pelas incertezas no qual observam-se dificuldades (para não dizer impossibilidades) na delimitação de parâmetros de condução da vida, a dimensão ética acaba por sofrer efeitos importantes. Como indica Martins (2007), vemos a passagem da descrição das certezas para uma análise dos valores, o que coloca o sujeito em posição em destaque no processo.

Ainda que as discussões filosóficas realizadas na modernidade sobre alteridade girassem em torno do primado do Eu sobre o Outro (sendo este tratado como como um meio para que o eu pudesse se reconhecer), a construção de novas proposições não produziu necessariamente o seu oposto. O que temos agora não é a centralidade de um eu psicológico,

\begin{tabular}{|c|c|c|c|c|}
\hline Q Rovista Dialeatus & Ano 10 & n. 22 & Edição Especial, junho 2021 & p. 84- 97 \\
\hline
\end{tabular}


mas sim, a necessidade de produção de um eu ético capaz de mediar as relações com um universo desconhecido o qual é impelido à condição de responsável.

Nesse sentido, entendemos que as pontuações trazidas nas discussões realizadas por Bauman em diálogo com Lévinas, conseguem produzir uma torção dos princípios da ética moderna ao conceder ao Outro um lugar prioritário a partir de sua condição de fragilidade frente a um eu potencialmente destrutivo em sua capacidade de categorização do que dele difere. Em uma relação pautada pela reciprocidade, o cuidado como expressão do amor ao diferente tornam-se traços importantes a serem desenvolvidos pela comunidade humana.

Por essa razão, a aposta na transposição da distância - separação sujeito-objetivo para a proximidade - própria das relações face-a-face - torna-se mais do que uma proposição, mas sim, um desafio nos tempos atuais atravessados pelas tecnologias e por relações a distância nas quais ao menor sinal de insatisfação com o Outro, basta desligar o smartphone.

Diferentemente do que muitas vezes encontramos propagado, a contemporaneidade não produz ou conduz ao fim da ética ou da moral, mas sim nos exige uma nova forma de tratar as questões vinculares, abrindo a possibilidade de através das emoções e dos afetos, resgatar a alteridade dos relacionamentos, de modo a exercitarmos a arte da vida.

\section{Referências}

BAUMAN, Z. O Mal-Estar na Pós-Modernidade. Rio de Janeiro: Jorge Zahar, 1998.

BAUMAN, Z. Ética Pós-Moderna. São Paulo: Loyola, 2003

BAUMAN, Z. A Arte da Vida. Rio de Janeiro: Jorge Zahar Editor, 2009.

BAUMAN, Z. Mundo Consumo: Ética del Indivíduos em La Aldea Global. Buenos Aires: Paidos, 2010.

BAUMAN, Z. Vida em Fragmentos. Rio de Janeiro: Jorge Zahar Editor, 2011.

BECK, U. Sociedade de Risco: rumo a uma outra modernidade. São Paulo: Ed. 34, 2010.

BITTENCOURT, R.N. A arte de amar na égide da liquidez. In: Revista Húmus, v. 9 n.27, p. 164-174, 2019.

BOCK, A.M; FURTADO, O; TEIXEIRA, M. Psicologias: uma introdução ao estudo das psicologias. São Paulo: Saraiva, 2008

CANDIOTTO, C. Ética: abordagens e perspectivas. Curitiba: Champagnat, 2010.

\begin{tabular}{|c|c|c|c|c|}
\hline Qevista Dialectus & Ano 10 & n. 22 & Edição Especial, junho 2021 & p. 84- 97 \\
\hline
\end{tabular}


CARRARA, O.V. Ética e Ontologia em Emmanuel Lévinas. Revista Estudos Filosóficos, n.8, 2012, p.33-50

CRITCHLEY, S. Introdução a Emmanuel Lévinas. In: HADDOCK-LOBO, R. Da existência ao infinito: ensaios sobre Emmanuel Lévinas. Rio de Janeiro, São Paulo: Ed. PUC-Rio, Loyola, 2006, p.13-20.

DERRIDA, J. Adeus a Emmanuel Lévinas. São Paulo: Perspectiva, 2008

FIGUEIREDO, L.C; COELHO JUNIOR, N.E. Figuras da intersubjetividade na constituição subjetiva: dimensões da alteridade. Interações, v. IX, n.17, jan-jun. 2004, p.928 .

FREIRE, W.F.A. A significação ética do Rosto em Emmanuel Lévinas. Dissertação de mestrado UECE fortaleza, 2007

HADDOCK-LOBO, R. Da existência ao infinito: ensaios sobre Emmanuel Lévinas. Rio de Janeiro, São Paulo: Ed. PUC-Rio, Loyola, 2006.

HERMANN, N. M. A. Breve investigação genealógica sobre o outro. In: Educação \& Sociedade, v. 32, 2011, p. 137-149,

JAMENSON, F. Pós-modernidade e sociedade de consumo. In: Novos estudos, São Paulo, n.12, jun.1985, p.16-26.

JUNIOR, J.F. Introdução a uma crítica da modernidade enquanto conceito sociológico. In: Mediações, v.15, n.2, jul, dez. 2010, p.28-41.

LEVINAS, É. Violência do rosto. São Paulo: Loyola, 2014

LÉVINAS, E. Totalidade e Infinito. Lisboa: Edições 70, 1980

LÉVINAS, E. Entre nós: Ensaios sobre a alteridade. Petrópolis: Editora Vozes, 2004

MARTINS, E.C. Da ética das certeza à ética dos valores pós-modernos. In: Revista de Educação PUC-Campinas, Campinas, n. 22, jun.2007, p. 25-40. Disponível em http://periodicos.puc-campinas.edu.br/seer/index.php/reveducacao/article/view/191/174

MIRANDA, J.V.A.M. Levinas e a reconstrução da subjetividade: aproximações com o campo da educação. Revista Brasileira de Educação v. 19 n. 57 abr.-jun. 2014. Disponível em http://www.scielo.br/pdf/rbedu/v19n57/v19n57a10.pdf.

NAVARRO, O. El «rostro» del otro: Una lectura de la ética de la alteridad de Emmanuel Lévinas Contrastes.In: Revista Internacional de Filosofía, v.VIII, 2008, p.177-194.

SILVA, P.F. Conceito de ética na contemporaneidade Segundo Bauman. São Paulo: Cultura Academica, 2013. 
SILVA, R.B. Lugares para amizade na sociedade contemporânea : caminhos educativos a partir da obra de Zygmunt Bauman. 2012. 194f. Tese (Doutorado em Educação) -

Universidade Estadual Paulista, Marília, 2012.

SILVA, R.B. Amizade, diferença e educação: reflexões a partir de Zygmunt Bauman. In: Educação \& Realidade, v. 43, n. 1, jan. mar. 2018, p. 115-129. 